\title{
COORPERATIVE LEARNING TYPE THINK PAIR AND SHARE (TPS) DENGAN KONTEKS EDUCATION SUSTAINABLE AND DEVELOPMENT UNTUK MENINGKATKAN KEMAMPUAN MENGANALISIS GEJALA DAN DAMPAK PEMANASAN GLOBAL
}

\author{
Mareza Riane Maharis ${ }^{\text {a) }}$, Taufik Ramlan Ramalis ${ }^{\mathrm{c}}$, Agus Fany Chandra \\ Wijaya $^{\text {c) }}$
}

Departemen Pendidikan Fisika Fakultas Pendidikan Matematika dan Ilmu Pengetahuan Alam Universitas Pendidikan Indonesia, Jl. Dr. Setiabudi No. 229, Bandung 40154, Indonesia

Email: a) $\underline{\text { marezarian97@ @ student.upi.edu }},{ }^{\text {b) }}$ taufik_lab.ipba@upi.edu,${ }^{\text {c) }}$ agus.fany@upi.edu

\begin{abstract}
Abstrak
Kemampuan menganalisis adalah salah satu keterampilan berpikir tingkat tinggi yang dianggap penting dilatihkan pada siswa melalui pembelajaran Fisika. Berdasarkan hasil studi pendahuluan, kemampuan ini masih belum maksimal dilatihkan kepada siswa dalam pembelajaran Fisika. Penelitian ini bertujuan menemukan cara terbaik untuk melatih kemampuan menganalisis melalui model pembelajaran Think Pair and Share (TPS), yang mengutamakan proses diskusi kelompok kecil sehingga siswa lebih dapat menganalisis masalah dan berkomunikasi satu sama lain. Model ini diterapkan melalui pendekatan Education Sustainable and Development (ESD) pada materi Pemanasan Global, untuk membangun Sustainability Awareness siswa terhadap lingkungannya. Desain penelitian menggunakan One Group Pretest-Posttest Design, dengan instrumen pilihan ganda untuk mengukur kemampuan berpikir analisis, angket untuk memprofilkan Sustainable Awareness.
\end{abstract}

Kata-kata kunci: (TPS); (ESD); Kemampuan Menganalisis; Sustainability Awareness.

\begin{abstract}
The ability to analyze is one of the high-level thinking skills that are considered important to be trained in students through learning Physics. Based on the results of the preliminary study, this ability is still not maximally trained for students in learning Physics. This study aims to find the best way to practice analytical skills through Think Pair and Share (TPS) learning models, which prioritizes the process of small group discussions so that students are better able to analyze problems and communicate with each other. This model is implemented through the Education Sustainable and Development (ESD) approach to Global Warming lessons, to build students' Sustainability Awareness of their environment. The research design uses One Group Pretest-Posttest Design, with multiple choice instruments to measure analytical thinking ability, questionnaire to profiling Sustainable Awareness.
\end{abstract}

Keywords: (TPS); (ESD); Analyzing Ability; Sustainability Awareness. 


\section{PENDAHULUAN}

Berdasarkan peraturan menteri pendidikan dan kebudayaan nomor 20 tahun 2016 tentang standar kompetensi lulusan pendidikan dasar dan menengah [1] pada dimensi pengetahuan tercantum bahwa setiap lulusan satuan pendidikan dasar dan menengah dituntut untuk mampu mengaitkan pengetahuan faktual, konseptual, prosedural dan metakognitif dalam konteks diri sendiri, keluarga, sekolah, masyarakat dan lingkungan alam sekitar, bangsa, negara, serta kawasan regional dan international. [2] Pendidikan memainkan peran kunci dalam membentuk kemampuan manusia untuk menyerap teknologi modern, dan untuk mengembangkan kapasitas agar tercipta pertumbuhan serta pembangunan yang berlanjut. Sehingga diperlukan pembelajaran yang efektif dan dapat dimaknai untuk diterapkan dalam kehidupan sehari-hari. Untuk menjawab permasalah tersebut UNESCO menyusun strategi sehingga tercipta gagasan Education for Sustainable Development (ESD) dengan harapan melalui pendidikan peserta didik dapat menyadari masalah yang terjadi di lingkungan serta mendapatkan dampak secara mental untuk setiap individu. [3] Pendidikan Berkelanjutan (ESD) pada dasarnya sebagai solusi untuk menyelesaikan masalah lokal yang bersifat global yang terjadi di Indonesia, seperti penebangan ilegal, limbah sampah yang tidak bisa didaur ulang serta kebiasaan masyarakat Indonesia yang belum sadar tentang kondisi lingkungannya. Sehingga dibutuhkan dilaksanakannya pembelajaran berkelanjutan yang secara prilaku dapat dikatakan sebagai Sustainability Awareness atau sikap peduli terhadap lingkungan yang dibagi menjadi tiga kategori yaitu kategori Sustainability practice awareness, Behavioral and attitude awareness, Emotional awareness yang diterapkan secara tersirat dalam pembelajaran.

Dalam materi fisika yang termasuk ilmu alam Education for Sustainable Development dapat diterapkan melalui proses pembelajaran dengan mengangkat masalah atau isu yang terjadi disekitar seperti pada materi Pemanasan Global. Fisika yang dianggap sebagai pelajaran sulit sehingga banyak peserta didik mengetahui jawaban tetapi tidak mengetahui makna dari pembelajaran tersebut. pada capaian PISA tahun 2014 Indonesia berada pada peringkat kedua terbawah untuk kategori membaca, berpikir analisis, berpikir sistesis dan aplikasi. [4] Kemampuan analisis adalah kemampuan peserta didik dalam menguraikan suatu informasi ke dalam unsur-unsur yang lebih kecil untuk menentukan keterkaitan antar unsur, lalu diklasifikasikan menjadi tiga yaitu: organizing, Attributing, Differentiating. [5] Kemampuan analisis ditunjukan dengan menguraikan pengetahuan ke bagianbagian yang lebih kecil dan mampu menunjukan hubungan antar bagian. Pada proses pembelajaran pemeran utama adalah seorang pendidik dan peserta didiknya dimana [6] guru sebagai pendidik terlalu banyak menggunakan waktunya untuk berbicara selama proses pembelajaran. Sehingga diciptakan banyak model pembelajaran yang terpusat pada peserta didik salah satunya adalah model pembelajaran Coorperative Learning Type Think Pair and Share (TPS) dengan Konteks Education For Sustainable Developent (ESD) dianggap sesuai untuk dilakukan sebagai jawaban dari permasalahan tersebut. Pada dasarnya cooperative learning dapat meningkatkan capaian pembelajaran [7-9]. Model ini juga dianggap sesuai karena dengan jumlah anggota kelompok untuk berdiskusi yang sedikit mendorong untuk setiap anggota terlibat dalam proses diskusi secara aktif sehingga peserta didik dapat secara aktif menganalisis gejala-gejala pemanasan global dengan mengaitkannya pada proses diskusi.

Pengaplikasian model pembelajaran Think Pair and Share dengan konteks Education for Sustainable Development terdiri dari beberapa tahap/ fase sebagai berikut.

TABEL 1. Langkah-langkah Operasional Model Pembelajaran TPS dengan Konteks ESD

\begin{tabular}{lll}
\hline No & Tahapan model TPS dengan Konteks & \\
\hline 1 & Pendahuluan & $\begin{array}{l}\text { Kerupa kegiatan penyampaian tujuan pembelajaran, kegiatan } \\
\text { Apersepsi dan pemberian motivasi }\end{array}$ \\
\hline 2 & Think & $\begin{array}{l}\text { Berupa kegiatan dimana guru menyajikan suatu masalah lalu } \\
\text { siswa dibimbing untuk mempelajari masalah tersebut sebelum } \\
\text { didiskusikan }\end{array}$ \\
\hline 3 & Pair & $\begin{array}{l}\text { Peserta didik mendiskusikan hasil pemikirannya terhadap } \\
\text { masalah dengan kelompok kecil yang terdiri dari dua orang dan } \\
\text { dibimbing oleh guru agar diskusi berjalan sesuai dengan arahan }\end{array}$ \\
\hline
\end{tabular}




\begin{tabular}{|c|c|c|}
\hline 4 & Share & $\begin{array}{l}\text { Peserta didik membagikan hasil pemikiran kelompok kecil } \\
\text { kepada kelompok yang lebih besar terdiri dari empat sampai } 6 \\
\text { orang tentang pemikirannya, lalu mendiskusikan kembali } \\
\text { masalah tersebut agar mendapatkan pernyataan yang sama } \\
\text { untuk setiap kelompok. Peran guru adalah sebagai pembimbing } \\
\text { proses diskusi serta membantu siswa yang tidak paham. }\end{array}$ \\
\hline 5 & Evaluasi & $\begin{array}{l}\text { Pada tahap ini setiap perwakilan kelompok membagikan } \\
\text { pemikirannya untuk seluruh kelas lalu setiap peserta didik } \\
\text { memiliki hak untuk bertamya ataupun mengoreksi pernyataan } \\
\text { temannya }\end{array}$ \\
\hline 6 & Pemberian penghargaan & $\begin{array}{l}\text { Penghargaan diberikan kepada seluruh peserta didik yang ikut } \\
\text { serta dalam proses diskusi. }\end{array}$ \\
\hline
\end{tabular}

\section{METODOLOGI}

Penelitian dilakukan dengan menggunakan design penelitian e-experimental designs dan menggunakan one group pretest posttest designs dimana hanya terdapat kelas experimen dengan diterapkan model Think Pair and Share (TPS) dengan Konteks Education for Sustainable Development (ESD). Sampel diambil dengan teknik sampling Confinience peserta didik kelas 11 SMA Negeri di Kota Bandung. Kelompok diberikan soal pretest dan posttest yang sama pada materi Pemanasan Global

Keterangan:

\begin{tabular}{|l|l|l|}
\hline $\mathrm{O}_{1}$ & $\mathrm{X}$ & $\mathrm{O}_{2}$ \\
\hline
\end{tabular}

$\mathrm{O}_{1}$ : pretest (tes awal kemampuan menganalisis peserta didik sebelum diberikan perlakuan)

$\mathrm{X}$ : Treatment (tahap pemberian perlakuan berupa penerapan model pembelajaran TPS dalam Konteks ESD)

$\mathrm{O}_{2}$ : Posttest (tes akhir kemampuan menganalisis peserta didik setelah diberikan perlakuan)

Desain penelitian tersebut peningkatan kemampuan menganalisis peserta didik dapat dilihat dari perbedaan hasil perolehan pretest dan posttest. Pada penelitian ini juga peneliti akan memprofilkan Sustainability Awareness peserta didik melalui angket. Instrumen yang digunakan dalam penelitian ini yaitu menggunakan instrumen pembelajaran dan instrumen pengumpulan data yang dijabarkan dalam tabel berikut:

TABEL 2. Instrumen Penelitian

\begin{tabular}{llll}
\hline \multirow{2}{*}{ Bentuk } & Tujuan & Teknik & \\
Instrumen & & Pengumpulan & Pengolahan Data \\
& & Data & \\
\hline RPP & Sebagai pendukung & Disajikan untuk & \\
(Rencana & terlaksananya proses & dua pertemuan (90 & \\
Pelaksanaan & pembelajaran & menit untuk setiap & \\
Pembelajaran & dengan model TPS & pertemuan) & \\
) & dalam Konteks ESD & & \\
& & & \\
\hline & Untuk melihat & Soal tes pilihan & Instrumen tes dianalisis dengan \\
Tes & peningkatan & ganda yang & menggunakan gain score \\
& kemampuan & digunakan ketika & \\
& menganalisis peserta & pretest dan & \\
\hline
\end{tabular}




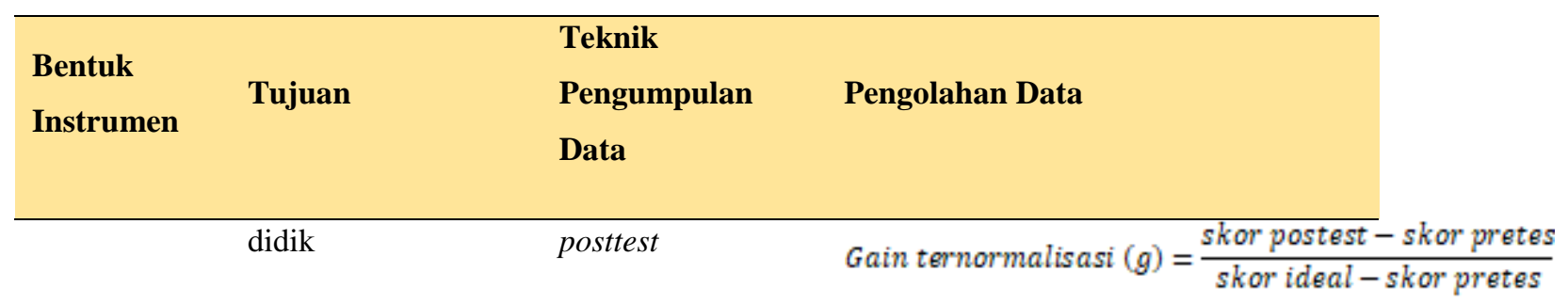

\begin{tabular}{llll}
\hline & & Terdiri dari 21 & Dianalisis menggunakan skala \\
Sebagai alat dalam & butir pernyataan & Guttman \\
memprofilkan & yang diadopsi dari & \\
Angket & Sustainable & jurnal dengan dua & Presentase $(\%)=\frac{\text { Jumlah shor yang diperoleh }}{\text { jumlah skor maksimum }} \times 100 \%$ \\
& Awareness peserta & pilihan jawaban \\
& didik & (setuju/tidak \\
& setuju)
\end{tabular}

HASIL DAN PEMBAHASAN

\section{A. Deskripsi Data Hasil Pembelajaran Model Think Pair and Share (TPS) dengan Konteks Education for Sustainable Development (ESD) pada Kemampuan Menganalisis}

Pada saat penelitian pretest dilakukan dengan menggunakan 20 butir soal pilihan ganda kemampuan menganalisis dalam waktu 90 menit. Setelah dilakukan pretest peserta didik diberikan perlakuan berupa penerapan model pembelajaran Think Pair and Share (TPS) dengan konteks Education for Sustainable Development (ESD). Lalu peserta didik diberikan posttest dengan soal yang sama dan waktu mengerjakan yang sama yaitu 90 menit. Instrumen test yang digunakan mencakup materi Pemanasan Global dan tingkat kognitif kategori C4 (Menganalisis).

Pengolahan data untuk mengetahui peningkatan kemampuan menganalisis diolah melalui n-gain ternormalisasi, sehingga didapatkan nilai sebagai berikut.

TABEL 3. Pengolahan Data dengan N-Gain Ternormalisasi

\begin{tabular}{llll}
\hline Pretest & Postest & n-gain & Kategori \\
\hline 44,09 & 79,09 & 0,63 & Sedang \\
\hline
\end{tabular}

Berdasarkan tabel diatas kemampuan menganalisis peserta didik mengalami peningkatan dilihat dari rerata hasil pretest dan postest serta nilai n-gain yang didapatkan sebesar 0,63 sehingga dapat dikatakan peningkatan kemampuan menganalisis peserta didik berada pada kategori sedang.

\section{B. Kemampuan Menganalisis Berdasarkan Kelompok Kemampuan Menganalisis Peserta Didik}

Kemampuan menganalisis peserta didik sebelumnya digunakan untuk mengukur secara keseluruhan kemampuan Peserta dikelas, untuk lebih detailnya dibawah ini disajikan data penelitian untuk mengetahui kemampuan menganalisis peserta didik berdasarkan kategori kemampuan menganalisis. 
TABEL 4. Sebaran Peserta Didik untuk setiap Kelompok Kemampuan

\begin{tabular}{|c|c|c|c|}
\hline & Tinggi & Sedang & Rendah \\
\hline $\begin{array}{l}\text { Rentang } \\
\text { pretest }\end{array}$ & $X \geq 55,58$ & $32,6<X<55,58$ & $X \leq 32,6$ \\
\hline Jumlah peserta didik & 3 & 23 & 7 \\
\hline
\end{tabular}

Setelah pengelompokan peserta didik berdasarkan kemampuannya didapatkan hasil bahwa terdapat tiga siswa dengan kemampuan tinggi, 23 siswa dengan kemampuan sedang dan tujuh siswa dengan kemampuan rendah. Lalu setiap kelompok tersebut dicari kembali nilai n-gain untuk setiap kelompok kemampuan peserta didik untuk melihat perubahan yang dialami setiap kelompok pada kemampuan menganalisis. Berikut adalah diagram yang menunjukkan perubahan kemampuan menganalisis peserta didik pada setiap kelompok kemampuan:

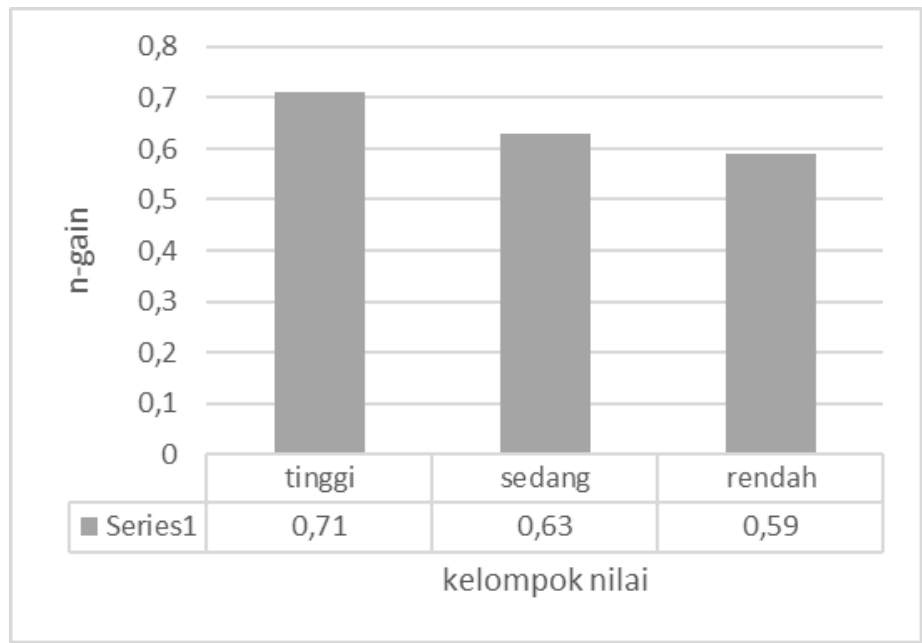

GAMBAR 1. Diagram Nilai N-Gain untuk setiap Kelompok Kemampuan

Berdasarkan diagram diatas dapat dilihat bahwa perolehan nilai n-gain untuk setiap kelompok siswa mendapatkan nilai dengan kategori tinggi pada kelompok siswa tinggi dan mendapatkan nilai n-gain ketegori sedang untuk kelompok siswa sedang dan rendah

\section{Kemampuan Menganalisis Setiap Aspek}

Kemampuan menganalisis yang diukur terdiri dari tiga aspek kemampuan yaitu Organizing, Atributting, dan Differentiating. Menggunakan nilai n-gain ternormalisasi dalam pengolahannya untuk mengetahui seberapa besar peningkatan kemampuan menganalisis peserta didik untuk setiap aspek sebelum dan sesudah penerapan model pembelajaran Think Pair and Share (TPS) dengan konteks Education for Sustainable Development (ESD). Sehingga didapatkan hasil pengolahan data sebagai berikut:

TABEL 5. Nilai n-gain setiap Kemampuan Menganalisis

\begin{tabular}{llll}
\hline $\begin{array}{l}\text { Aspek Kemampuan } \\
\text { Menganalisis }\end{array}$ & Pretest & Posttest & $\overline{\mathbf{g}}\rangle$ \\
\hline Organizing & 13,64 & 23,9 & 0,63 \\
\hline Attributing & 14,55 & 29,1 & 0,57 \\
\hline Differentiating & 15,30 & 25,6 & 0,70 \\
\hline
\end{tabular}

Berdasarkan tabel diatas dapat dikatakan bahwa semua aspek kemampuan menganalisis mengalami peningkatan dilihat dari hasil pretest dan postest dan untuk perolehan nilai n-gain berada pada kategori sedang untuk Aspek Organizing dan Attributing dan berada pada kategori tinggi untuk Aspek Differentiating.

\section{Profil Sustainable Awareness}

Memprofilkan Sustainability Awareness yang terdiri dari tiga aspek yaitu Sustainability practice awareness, Behavioral and attitude awareness, Emotional awareness peserta didik diukur dengan bantuan 
instrumen berupa angket dan diolah menggunakan skala Gutman, Angket diujikan kepada peserta didik SMA kelas XI IPA sehingga didapatkan hasil pengolahan angket sebagai berikut:

TABEL 6. Persentase Respon Positif Pada Setiap Kategori Sustainability Awareness

\begin{tabular}{|c|c|c|c|}
\hline $\begin{array}{l}\text { Kategori } \\
\text { Awareness }\end{array}$ & Sustainability & $\begin{array}{ll}\text { Persentase } & \text { respon } \\
\text { positif }(\%) & \end{array}$ & keterangan \\
\hline $\begin{array}{l}\text { Sustainability } \\
\text { awareness }\end{array}$ & practice & 73,59 & Sudah sering dilakukan \\
\hline $\begin{array}{l}\text { Behavioral } \\
\text { awareness }\end{array}$ & attitude & 80,09 & Sudah sering dilakukan \\
\hline Emotional awa & ireness & 98,70 & Sudah sering dilakukan \\
\hline
\end{tabular}

Berdasarkan tabel diatas dapat dikatakan secara keseluruhan bahwa ketiga kategori dari Sustainability Awareness sudah sering dilakukan oleh setiap individu yang menjadi peserta didik.

\section{PEMBAHASAN}

\section{A. Pengaruh Penerapan Model Pembelajaran TPS Dengan Konteks ESD Terhadap Kemampuan Menganalisis}

Hasil penelitian terhadap sampel yaitu kelas XI IPA memperlihatkan adanya perbedaan tingkat kemampuan dari sebelum pembelajaran dan setelah pembelajaran. Tahap pembelajaran yang dilakukan dengan menggunakan enam tahapan berupa 1) fase pendahuluan, 2) fase Think, 3) fase Pair, 4) fase Share, 5) fase evaluasi dan 6) pemberian penghargaan. Setelah dilakukan pretest, pemberian perlakuan, dan posttest dengan soal yang sama terlihat terdapat peningkatan untuk kemampuan menganalisis secara umum untuk setiap sampel dibuktikan dengan perolehan nilai n-gain sebesar 0,63 yang termasuk kedalam kategori sedang.

Selain melihat peningkatan kemampuan menganalisis secara umum, dilakukan pula pengolahan data secara kelompok kemampuan siswa yang dibagi menjadi tiga kelompok yaitu kelompok tinggi, sedang dan rendah dilihat dari perolehan nilai pretest sehingga didapatkan pembagian kelompok tinggi sebanyak tiga orang, kelompok sedang sebanyak 23 orang dan kelompok rendah sebanyak 7 orang. Selanjutnya data pretest dan posttest setiap kelompok dicari nilai n-gain untuk dilihat peningkatannya yang menghasilkan bahwa pada kelompok tinggi mendapatkan nilai n-gain sebesar 0,71 yang termasuk dalam kategori tinggi lalu untuk kelompok kemampuan sedang dan rendah masing-masing mendapatkan nilai 0,63 dan 0,59 yang termasuk kedalam kategori sedang. Sehingga dapat dikatakan kemampuan menganalisis dengan penerapan model pembelajaran Think Pair and Share (TPS) dengan konteks Education for Sustainable Development (ESD) meningkat, terutama bagi kelompok peserta didik tinggi dan secara umum meningkat untuk setiap kelompok kemampuan.

Dilakukan pula pengolahan peningkatan kemampuan menganalisis untuk setiap aspek dari kemampuan menganalisis yang terdiri dari aspek Organizing, Attributing, Differentiating menggunakan perolehan nilai n-gain. Sehingga didapatkan nilai n-gain untuk aspek Organizing dan Attributing masingmasing 0,63 dan 0,57 berada pada kategori sedang, hal tersebut menunjukkan bahwa penerapan model pembelajaran Think Pair and Share (TPS) dengan konteks Education for Sustainable Development (ESD) dalam pembelajaran cukup dapat meningkatkan kemampuan menganalisis peserta didik pada Aspek tersebut. sedangkan nilai n-gain pada Aspek Differentiating dengan nilai n-gain 0,70 berada pada kategori tinggi, sehingga dapat dikatakan bahwa dengan menerapkan model pembelajaran Think Pair and Share (TPS) dengan konteks Education for Sustainable Development (ESD) dapat meningkatkan kemampuan menganalisis khususnya pada aspek Differentiating.

\section{B. Pengaruh Penerapan Model Pembelajaran TPS Dengan Konteks Esd Terhadap Profil Sustainability Awareness}

Pada saat penelitian selain dilakukan uji terhadap kemampuan menganalisis dilakukan pula uji terhadap profil sustainability awareness yang terdiri dari tiga aspek peserta didik dengan menggunakan angket dan didapatkan hasil bahwa secara keseluruhan bahwa ketiga kategori dari Sustainability Awareness sudah sering dilakukan oleh setiap individu yang menjadi peserta didik.

Pada kategori Sustainability practice awareness atau upaya sadar akan lingkungan memperoleh nilai presentase 73,59\% secara umum hampir semua pernyataan mendapatkan respon positif yang artinya banyak dari peserta didik yang telah melakukan kegiatan tersebut. Pada kategori kedua yaitu Behavioral and attitude awareness yang berbicara tentang sikap peserta didik terhadap lingkungan. Respon positif yang diterima oleh 
kategori ini sangat banyak terlihat dari perolehan presentase respon positif pada tabel senilai 80,09 yang berada pada kategori sering dilakukan, dari nilai tersebut dapat disimpulkan bahwa peserta didik telah memiliki sikap terhadap lingkungannya. Pada kategori ketiga yaitu Emotional awareness atau bisa dikatakan sebagai kepedulian terhadap lingkungan dari segi emosi. Respon positif yang diperoleh oleh kategori ini adalah senilai 98,70 yang dapat diartikan sering dilakukan oleh peserta didik Ketiga kategori dari Sustainability Awareness secara langsung dapat mendukung konsep ESD dilihat dari hasil perolehan profil Sustainability Awareness yang mendapatkan kategori tinggi untuk ketiganya, seingga dapat dikatakan bahwa sikap peserta didik sudah dapat mendukung konsep ESD.

\section{SIMPULAN}

Berdasarkan hasil dan pembahasan dapat ditarik kesimpulan bahwa terdapat peningkatan kemampuan menganalisis peserta didik untuk setiap kelompok kemampuan dan setiap aspek dari kemampuan menganalisis setelah diterapkannya model pembelajaran TPS dengan konteks ESD berdasarkan perolehan nilai n-gain yang berada pada kategori sedang dan tinggi. Serta peserta didik juga terbukti memiliki Sustainability Awareness untuk ketiga kategori berdasarkan hasil pengolahan yang menunjukkan hasil pada kategori tinggi untuk ketiga kategori. Dalam pelaksanaan model pembelajaran TPS dengan konteks ESD hendaknya guru menyeimbangi pemberian hands on dan mind on pada peserta didik agar peserta didik dapat melaksanakan pembelajaran dengan baik.

\section{REFERENSI}

[1] Peraturan Menteri Pendidikan dan Kebudayaan Nomor 20 Tahun 2016 "Standar Kompetensi Lulusan Pendidikan Dasar Dan Menengah”, Permendikbud, Jakarta, 2016.

[2] Todaro, Michael dan Smith, Stephen."Pembangunan ekonomi di dunia ketiga jilid 2". Jakarta: Erlangga, 2003.

[3] Bayu, N. "Education for Sustainable Development (ESD) sebuah upaya Mewujudkan Kelestarian Lingkungan". Sosio Didaktika : Social Science Education Journal. 2015, 2 (1),22-30.

[4] Anderson, Rin W dan David R.Krathwohl. " A Taksonomi for Learning, Teaching, and Assesing: A Revision of Bloom's Taksonomi of Educational Objectives". New York: Addison Wesley Longman,2010.

[5] Munthe, Bermawy. "Desain Pembelajaran". Yogyakarta: Pustaka Insan Mandiri, 2009.

[6] Arend, Richard. Learning To Teach. Boston: Mcgraw-hill, 2004.

[7] G. D. Sucinta, H. Novia, and S. Feranie, "Penerapan Strategi Metakognisi pada Cooperative Learning Tipe STAD untuk Melihat Perkembangan Metakognisi Siswa pada Materi Elastisitas", jpppf, vol. 2, no. 1, pp. 43 - 50, Jun. 2016.

[8] S. Suhardi, S. Hanaping, and M. A. Said, "Peningkatan Hasil Belajar Fisika Melalui Model Pembelajaran Kooperatif Tipe Team Assisted Individualization pada Siswa Kelas VII.D SMP Negeri 2 Bangkala Kabupaten Jeneponto”, jpppf, vol. 1, no. 2, pp. 89 - 96, Dec. 2015.

[9] I. A. Khairati, S. Feranie, and S. Karim, "Penerapan Strategi Metakognisi pada Cooperative Learning untuk Mengetahui Profil Metakognisi dan Peningkatan Prestasi Belajar Siswa SMA pada Materi Fluida Statis", jpppf, vol. 2, no. 1, pp. 65 - 72, Jun. 2016. 
